\title{
Knowledge of users of low-dose oral combined contraceptives about the method
}

\author{
Camila Félix Américo ${ }^{1}$ \\ Paula Sacha Frota Nogueira ${ }^{2}$ \\ Rebeca Pinho Romero Vieira ${ }^{3}$ \\ Cleide Gomes Bezerra ${ }^{4}$ \\ Escolástica Rejane Ferreira Moura ${ }^{5}$ \\ Marcos Venícios de Oliveira Lopes ${ }^{5}$
}

\begin{abstract}
Objectives: to identify the knowledge of users of combined oral contraceptive about correct use, side effects and complications; to verify the correlation between knowledge about the method with age, education, family income and time of use. Method: cross-sectional study performed in Fortaleza, Ceará, Brazil, from March to July 2010, with 294 women. Data were collected through interviews. Results: $75 \%$ had substantial knowledge about the proper use and side effects and no knowledge about complications. The higher the educational level and family income, the higher the women's knowledge about the correct use of the method. Positive correlation suggests that women who used the method for longer knew more about its side effects. Conclusion: there are knowledge gaps about the method, which are influenced by socioeconomic variables and use time.
\end{abstract}

Descriptors: Contraceptives, Oral, Combined; Knowledge; Socioeconomic Factors.

\footnotetext{
${ }^{1}$ Doctoral student, Departamento de Enfermagem, Universidade Federal do Ceará, Fortaleza, CE, Brazil.

2 MSc, Professor, Universidade de Fortaleza, Fortaleza, CE, Brasil.

${ }^{3}$ Master's student, Departamento de Enfermagem, Universidade Federal do Ceará, Fortaleza, CE, Brazil. Scholarship holder from Programa de Orientação e Operacionalização da Pós-Graduação Articulada à Graduação (PROPAG/REUNI).

${ }^{4}$ Master's student, Departamento de Enfermagem, Universidade Federal do Ceará, Fortaleza, CE, Brazil.

${ }^{5} \mathrm{PhD}$, Associate Professor, Departamento de Enfermagem, Universidade Federal do Ceará, Fortaleza, CE, Brazil.
}

\section{Corresponding Author:}

Escolástica Rejane Ferreira Moura

Universidade Federal do Ceará. Departamento de Enfermagem

Rua Alexandre Baraúna, 1115

Bairro: Rodolfo Teófilo

CEP: 60430-160, Fortaleza, CE, Brasil

E-mail: escolpaz@yahoo.com.br 


\section{Introduction}

The use of combined oral contraceptives (COC) is increasing in Brazil. Data from the last National Survey on Demographics and Health of Children and Women (NSDH) conducted in 2006 revealed that $24.7 \%$ of women with partners used $\mathrm{COC}$ as Contraceptive Method (CM). That represents an increase of $4.0 \%$ compared to the percentage found in the NDSH in 1996, when the percentage of method use among women with partners was $20.7 \%{ }^{(1-2)}$.

Its efficacy depends on correct use, which is the woman's responsibility herself to control, by using it every day, regularly and starting the cards on appropriate days. A failure rate of eight pregnancies to 100 users each year is estimated when considering the typical use. However, if there are no errors in usage, less than a pregnancy can occur for 100 women/year(3).

The misuse of COC is directly related to increased rates of method failure, as well as to increased side effects, an important reason for discontinuation of use ${ }^{(4)}$.

In this context, the Brazilian Ministry of Health, based on the "Selected Practice for Contraceptive Use," of the World Health Organization (WHO), provides technical information on the proper use of COC and orientates users to be informed about the relative efficacy of the method, about correct use, its common side effects, complications, and the risks and about the benefits of the method for health ${ }^{(5-6)}$.

Ensuring an informed, deliberate and oriented choice of $\mathrm{COC}$ to the adequate conduct of the user towards the common side effects minimize the chances of use interrruption, unplanned and/or unwanted pregnancy and provoked abortion ${ }^{(4,7)}$.

The practical use of $\mathrm{COC}$ and possible complications are still unknown for most of the users. Beliefs and myths that relate the use of $\mathrm{COC}$ with infertility and cervix cancer, for example, persist among women and, not infrequently, that information is disseminated by health professionals(8-10). Therefore, despite the clearly defined recommendations about what should be informed by health professionals in the "Selected Practice for Contraceptive Use" gaps in users knowledge seem to prevail, justifying this research.

Given this context, and considering that, due to better tolerability, low-dose COC is the hormonal contraceptive of choice, the most available in the Unified Health System (SUS) and the most used, the following questions arise: What do low-dose COC users know about the use, side effects and possible complications of this method? What are the determinants of not knowing? In order to answer these questions, the objectives defined were: to identify the knowledge of low-dose COC users about to the correct use of the method, side effects and complications, and to verify the correlation between knowledge about correct use with age, education, family income and time of use of the method.

\section{Methods}

Cross-sectional, exploratory study, performed at the Municipal Health System of Fortaleza, capital of Ceará State, northeastern Brazil.

The population was 841,481 women of childbearing age (10-49 years) at the city(11). A sample of 264 women was calculated by the formula used for infinite populations, with confidence level of $95 \%$, sampling error of $5 \%$ and $p$ ratio of $22.1 \%$. The $P$ value was based on the prevalence of COC users of NSDH of $2006^{(1)}$.

Participants were selected based on the following inclusion criteria: being of childbearing age and using low-dose COC. Low-dose COC is identified by the parameter of having estrogen dosage less than or equal to $0.035 \mathrm{mg}^{(3)}$. Women who received contraceptive care in private health services were excluded.

Once the user was asked about the commercial name of the COC, its estrogen level was checked through a framework developed by the authors. When the dosage was less than or equal to $0.035 \mathrm{mg}$, therefore low, the research continued. The framework reunited 34 different $\mathrm{COC}$ presentations available in the public health system and in local pharmacies, with their respective trade names and dosage of estrogen.

Data were collected from March to July 2010 in seven Basic Health Units (BHU) distributed in six different health regions of Fortaleza-CE, defined by a raffle. Women were recruited in the waiting rooms of different services offered at the BHU (family planning, child care, prevention of cervical cancer and HypertensionDiabetes Program), when the interviewer asked: "Which of you here uses contraceptive pills?". The pill user, once accepting to participate in the survey, was escorted to a private place in the unit for the interview.

The interview form had questions about age, marital status, education, family income and time of use of low-dose COC. In order to identify knowledge about the correct use, side effects and complications with the use of the method, three Likert scales constructed by the authors were applied, respectively, based on the assumptions established by WHO for the selected 
practice of $\mathrm{CM}^{(6)}$. The scales have not been validated, which constitutes a limitation of the study.

Each scale item received punctuation, with the knowledge classified according to the number of correct answers in each scale. When the participant did not mention any item of the scale, her knowledge was considered None (scale level 1); when the participant cited one item, her knowledge was considered limited (scale level 2); when the participant cited two items, knowledge was considered moderate (scale level 3); when the participant cited three items, knowledge was considered substantial (scale level 4); and when all items were cited, knowledge was considered extensive (scale level 5).

On the scale of assessment of knowledge about the correct use of the method, the items were: the participant reports that the start of the pill pack must be in the first five days after the beginning of menstruation or at any period of the menstrual cycle since not pregnant and after this period starting at any time, provided she is sure that she is not pregnant, associating a complementary method for seven days; the beginning of the subsequent pill pack should occur seven days after the end of the previous pack; the pill should be taken daily and always in the same schedule; when one forgets to take one or two pills, one should take a pill as soon as possible and follow the usual time or take both at the same time; if one recognizes that there is vomiting within two hours after ingestion of the pill, one should take another pill.

The items of the scale of assessment of knowledge about side effects were: the participant recognizes changes in the menstrual pattern (reduction, irregularity and lack of menstrual flow); recognizes changes in the nervous system (mood alterations, irritability, dizziness and headache); recognizes changes on the gastrointestinal system (abdominal pain, nausea and vomiting); recognizes other systemic changes (breast tenderness, weight change).

In the assessment of knowledge about complications the following items were adopted: the participant reports blood clot in the deep veins of the legs (deep vein thrombosis); stroke; myocardial infarction (heart); increased blood pressure.

The data were analyzed in the Statistical Package for Social Sciences for Personal Computer (SPSS-PC), version 13.0 through descriptive and inferential statistics using absolute and relative frequencies, mean $(\chi)$, Standard Deviation (SD), percentiles and confidence intervals (IC). The confidence intervals were used to estimate the value of the proportion of women who demonstrated adequate knowledge about each of the topics valued. Thereby, it is considered, with a $95 \%$ confidence, that the true percentage of women who would correctly answer a given item is a value within the range built.

The Kolmogorov-Smirnov test was used to check if the distribution of quantitative variables was normal. The Spearman's correlation coefficient was calculated to determine the linear relationship between two continuous variables. For this study the correlations were classified as follows: $0 \leq|\rho|<0.2$ - very weak; $0.2 \leq|\rho|<0.4$ - weak, $0.4 \leq|\rho|<0.6$ - moderate, $0.6 \leq|\rho|<0.8$ - strong, $0.8 \leq|\rho| \leq 1.0$ - very strong. The analysis of the level of knowledge was dibe by the description of the global average of the three types of knowledge assessed, and followed the same logic of level classification for each individual, ranging from No knowledge (value 1) to Extensive knowledge (value 5). Thereby, no arbitrary cutoff point was adopted to dichotomize individuals in levels of knowledge, such as adequate or inadequate.

The project was approved by the Ethics Committee of Universidade Federal do Ceará, Protocol N. 04/10. The recommendations of Resolution 196/96 of the National Health Council were abided, which deals with research involving humans. Each participant signed a consent form for each participant.

\section{Results}

The participants were mostly young, predominantly between 20 to 28 years old, accounting for 139 (52.7\%). However, the age ranged from 15 to 46 years old, with a considerable number of adolescents (11.8\%). A stable relationship with a regular partner was reported by 222 (84.1\%) participants.

Complete secondary education prevailed, corresponding to 124 (47\%) participants. However, this variable ranged from no schooling to complete higher education. The participants lived with an average of 3.9 persons per family $(S D= \pm 1.50)$ and an average income of 2.4 minimum wages $(S D= \pm 0.85)$. That allows the inference about a socioeconomic unfavorable situation of the group.

Half the participants had "substantial" knowledge (scale level 4 ) or higher $\left(P_{75}=4.00\right)$ both about the proper use of $\mathrm{COC}$ and about its side effects. The knowledge regarding complications was the weakest, about which $75 \%$ of women showed no knowledge $\left(P_{75}=1.00\right)$ (Table 1). 
Table 1 - Distribution of the number of low-dose COC users according to the level of knowledge about correct use, side effects and complications of the method. Fortaleza Health System, CE, Brazil, 2010

\begin{tabular}{|c|c|c|c|c|}
\hline & \multirow{2}{*}{ Mean ( $\pm S D)$} & \multicolumn{3}{|c|}{ Percentiles } \\
\hline & & $\mathbf{P}_{25}$ & $P_{50}$ & $P_{75}$ \\
\hline \multicolumn{5}{|l|}{ Knowledge } \\
\hline Correct use & $3.72( \pm 0.95)$ & 3.00 & 4.00 & 4.00 \\
\hline Side effects & $3.50( \pm 1.11)$ & 3.00 & 4.00 & 4.00 \\
\hline \multirow[t]{2}{*}{ Complications } & $1.13( \pm 0.43)$ & 1.00 & 1.00 & 1.00 \\
\hline & $\mathbf{N}$ & $\%$ & \multicolumn{2}{|c|}{$\mathrm{Cl}(95 \%)$} \\
\hline \multicolumn{5}{|l|}{ Correct use } \\
\hline Reports that the pill should be taken daily and always at the same time schedule. & 223 & 84.5 & \multicolumn{2}{|c|}{$79.5-88.6$} \\
\hline Correctly reports what to do if she forgets to take the pill. & 213 & 80.7 & \multicolumn{2}{|c|}{$75.4-85.3$} \\
\hline $\begin{array}{l}\text { Reports that the start of the pill pack must be in the first five days after the beginning of } \\
\text { menstruation or at any period of the menstrual cycle since not pregnant }\end{array}$ & 174 & 65.9 & \multicolumn{2}{|c|}{ 59.8-71.6 } \\
\hline $\begin{array}{l}\text { Reports the beginning of the subsequent pill pack should occur seven days after the } \\
\text { end of the previous pack }\end{array}$ & 110 & 41.7 & \multicolumn{2}{|c|}{$35.7-47.9$} \\
\hline \multicolumn{5}{|l|}{ Side effects } \\
\hline Recognizes alterations in the nervous system. & 204 & 77.3 & \multicolumn{2}{|c|}{ 71.7-82.2 } \\
\hline Recognizes other systemic alterations. & 177 & 67.0 & \multicolumn{2}{|c|}{$61.0-72.7$} \\
\hline Recognizes alterations in the gastrointestinal system & 167 & 63.3 & \multicolumn{2}{|c|}{$57.1-69.1$} \\
\hline Recognizes alterations in the menstrual pattern & 116 & 43.9 & \multicolumn{2}{|c|}{$37.9-50.2$} \\
\hline \multicolumn{5}{|l|}{ Complications } \\
\hline Increased arterial blood pressure & 15 & 5.7 & \multicolumn{2}{|c|}{$3.2-9.2$} \\
\hline Stroke & 8 & 3.0 & \multicolumn{2}{|c|}{$1.3-5.9$} \\
\hline Acute myocardial infarction & 6 & 2.3 & \multicolumn{2}{|c|}{$0.8-4.9$} \\
\hline Deep vein thrombosis & 5 & 1.9 & \multicolumn{2}{|c|}{$0.6-4.4$} \\
\hline
\end{tabular}

$\mathrm{P}_{25}$ : Percentile 25; $\mathrm{P}_{50}$ : Percentile 50 or median; $\mathrm{P}_{75}$ : Percentile 75; CI: Confidence interval

Daily use of the pill at a regular time was the item that participants were the most correct about regarding the correct use of the method $(84.5 \%, 95 \%$ $\mathrm{CI}=79.5-88.6)$; the correct start of the subsequent pill pack was mentioned by $41.7 \%$ of participants ( $95 \%$ $\mathrm{CI}=35.7-47.9$ ), the item that participants were the most wrong about in this knowledge area. Thus, the knowledge gap in the research group regarding the items assessing the correct use of $\mathrm{COC}$, was about what to do if one forgets one or more pills, as well as the beginning of the first pack or subsequent pack.

Regarding the knowledge about side effects, up to $75 \%$ of participants had "substantial" knowledge and "changes in the nervous system" were cited by $77.3 \%$ of participants ( $95 \% \mathrm{CI}=71.7-82.2 \%)$. Changes in menstrual pattern were cited by $43.6 \%$ of participants ( $95 \% \mathrm{CI}=$ 37.9-50.2), the least cited side effects. Nevertheless, this frequency can be considered relatively high.

Regarding complications related to the use of lowdose COC, $75 \%$ of women had no knowledge. Increased blood pressure and deep vein thrombosis were the most and least known complications, reported by $5.7 \%$ (95\% CI $=3.2-9.2$ ) and $1.9 \%(95 \% \mathrm{CI}=0.6-4.4 \%)$ of participants, respectively.
Table 2 shows that knowledge about the correct use of low-dose COC significantly correlates positively with schooling and family income, suggesting that the higher the education $(r=0.164, p=0.008)$ and/or family income $(r=0.135, p=0.029)$, the greater the knowledge of the participants on the proper use of COC. Women with higher educational level also knew more about the complications related to the use of the method ( $r=0.166$, $p=0.007)$. All these correlations are considered very weak by the classification adopted.

Table 2 - Correlation between knowledge about the correct use with age, education, family income and time of $\mathrm{COC}$ use, knowledge about side effects with time of COC use and complications with education. Fortaleza Health System, CE, Brazil, 2010

\begin{tabular}{lcc}
\hline & $\rho$ & p-value \\
\hline Knowledge about the correct use of COC & & \\
Age & -0.063 & 0.308 \\
Education & 0.164 & 0.008 \\
Monthly family income & 0.135 & 0.029 \\
Time of COC use & 0.023 & 0.712 \\
& & (continue...)
\end{tabular}

(continue...) 
Table 2 - (continuation)

\begin{tabular}{lcc}
\hline & $\rho$ & p-value \\
\hline $\begin{array}{l}\text { Knowledge about side effects } \\
\text { Time of COC use }\end{array}$ & 0.189 & 0.002 \\
$\begin{array}{l}\text { Knowledge about complications related } \\
\text { to the use of COC }\end{array}$ & & \\
$\quad$ Education & 0.166 & 0.007 \\
\hline
\end{tabular}

Regarding knowledge about side effects, the very weak positive correlation suggests that women who used COC longer knew more about its side effects ( $r=$ $0.189, p=0.002$ ).

\section{Discussion}

The predominance of "substantial" knowledge about the correct use and side effects related to lowdose COC among participants may be due in part to the investment of the Ministry of Health in this area of care, prioritizing since the $80 \mathrm{~s}$, promoting Family Planning (FP) services to the population, based on free and informed choice of the $\mathrm{CM}$, recommending health professionals to conduct educational activities on the general characteristics of the CM.

The female autonomy and the interest about the control of offspring, linked to women insertion in the labor market and increased competitiveness of this market, requiring women more years of studies and further refinement improvement, with the expansion of information through informal channels, like the internet, have also contributed to this result.

However, there is lack of women's knowledge about the correct start of low-dose COC pack, on the regularity of the time to take the pill and on the measures to be adopted when one forgets to take one or more pills.

Inadequate knowledge about the start of COC packs fell was about the interval required to start the first pack and subsequent packs. Regardless of the first or subsequent pack, participants reported to "start the pack on the fifth day of menstruation". It is known that for better effectiveness of this $\mathrm{COC}$, ti should preferably be started on the first day of the menstrual cycle or until the fifth day and a seven-day interval between a pack and the next should occur, and the user must initiate use regardless of the day menstrual cycle ${ }^{(3)}$.

One of the basic points to be considered to guarantee the efficacy of low-dose COC is daily taking at a regular time. Health professionals may discuss with their clients tips related to pill use, i.e., how to associate the time to take the pill with some daily activity. In this regard, it is important to inform users about how regular ingestion of the pill contributes to the reduction of side effects $^{(3)}$.

There is, therefore, the need for improved knowledge of the participants, because they showed themselves exposed to increased risks of $\mathrm{COC}$ failure and side effects due to lack of knowledge about the correct use of the method.

Forgetting one or more pills can be faced by the user in different ways, depending on the number of missed pills: from one to three pills, there is a chance to keep using the same pack with little harm to the efficacy of the method; when more than three pills are forgotten, the pack in use must be interrupted and the woman must wait for the next menstrual period and start a new pack ${ }^{(3)}$.

In the assessment of knowledge about side effects, substantial knowledge prevailed (scale level). Because they are unpleasant sensations, it is possible that women are more interested in clarifying its occurrence with health professionals or even in social life. It is also likely that health professionals, during FP consultations, orientate women about the most common side effects in order to avoid interruption of the use of the method. Authors claim that the use of the CM sought by women may be affected or suspended by the lack of knowledge.

It is assumed, yet, that adequate information about the side effects is being acquired by most study participants. Information about CM enables free choice of the method, tahe basic right to be provided to clients according to Law N. 9263/1996, about FPin Brazil. In particular, information about COC side effects of will reduce fear and insecurity of women, as well as provide better observation of those, greater persistence in continuing to use the method, clarification about myths related to its use and greater satisfaction with the use.

Regarding complications related to $\mathrm{COC}$ use, increased blood pressure and deep vein thrombosis were the most and least known complications, reported by $15(5.7 \%, 95 \% \mathrm{CI}=3.2-9.2)$ and $5(1.9 \%$, $95 \%$ CI $=0.6-4.4 \%$ ) participants, respectively. This was the area of the lowest knowledge. The risks mentioned by women exposed were different from the literature ${ }^{(3)}$ and, unlike the systemic complications such as deep vein thrombosis, myocardial infarction and stroke, women reported complications in the female reproductive system, i.e., 132 (50\%) reported mass accumulation in the uterus which, according to some participants, the "physician said" "scratch", cysts or tumors, infertility, inflammation and loss of action by prolonged use. 
Therefore, the perceptions in this knowledge were incorrect and underlie individual-user, community, but can also permeate health professionals who, not knowing or neglecting the transfer of information to customers, end up contributing to sedimentation of these myths, thereby, when the unveiling the correct information should occur ${ }^{(8)}$.

The incorrect use of COC by women makes them vulnerable to unplanned pregnancy, since the efficacy of the method in these circumstances is compromised ${ }^{(3)}$.

This vulnerability is not confined, however, to developing countries, such as Brazil. Unplanned pregnancy in the presence of $\mathrm{CM}$ use is a reality also faced in countries such as Vietnam, United Kingdom and United States ${ }^{(5,13-14)}$. In those countries, incorrect use of $\mathrm{CM}$ is also evidenced as well as the need to implement educational strategies that engage individuals to perceive themselves at risk for unplanned pregnancy due to inadequate use of the method.

In a study performed with 278 adolescents in the city of Teresina-PI, a questionnaire and scales were used in order to measure objective knowledge about the use of oral contraceptives. In order to be considered as having adequate objective knowledge, it was necessary to answer correctly the four items in the scale that addressed their correct use of the method. It was found that $98.2 \%$ of these adolescents had low objective knowledge. The authors concluded that the lack of knowledge reflects the need for more accessible communication techniques ${ }^{(15)}$.

In the sample of the present study, there was greater knowledge about the correct use of COC among women with higher education and better economic situation; the better these conditions, the better the knowledge level (positive Spearman's correlation).

In Brazil, the decline in fertility was higher in more developed regions of the country, confirming the relationship between socioeconomic status and effectiveness in contraceptive use ${ }^{(1,16)}$.

Information about low-dose COC among women in this study should be provided with higher effectiveness. For such, activities of individual and collective orientation should not be punctual, circumscribed to the delivery of COC packs monthly, but developed in several opportunities for attention to their health as a priority area of care.

\section{Conclusion}

The participants had, in general, "substantial" knowledge level about the correct COC use and side effects and "No" knowledge about complications with the use of COC. The knowledge about the correct use of $\mathrm{COC}$ was higher among women with higher education and better economic situation, i.e., the better these conditions, the better the level of this knowledge.

It is necessary that professionals in primary health care, especially nurses, develop strategies for health education in order to promote the acquisition of knowledge by COC users about the method. Supporting by the management of the local health system is fundamental, in order to ensure the necessary logistics to primary care teams.

The non-validation of the Likert scales used in this study constitutes a limitation of the research. Therefore, it is suggested for future research both the validation of such scales and the assessment of the impact of health education strategies aimed at improving knowledge of coc users.

\section{References}

1. Ministério da Saúde (BR). PNDS 2006- Pesquisa Nacional de Demografia e Saúde da Mulher e da Criança. Brasília: Ministério da Saúde; 2008.

2. Sociedade Bem-estar Familiar no Brasil (BEMFAM). Pesquisa Nacional sobre Demografia e Saúde. Rio de Janeiro: BEMFAM; 1997.

3. World Health Organization (WHO) and Johns Hopkins Bloomberg School of Public Health/Center for Communication Programs (CCP), INFO Project. Family Planning: A Global Handbook for Providers. Baltimore (MD); 2007.

4. Bahamondes L, Pinho F, Melo NR, Oliveira E, Bahamondes MV. Associated factors with discontinuation use of combined oral contraceptives. Rev Bras Ginecol Obstet. 2011;33(6):303-9.

5. Duong DV, Lee AH, Binns CW. Contraception within six-month postpartum in rural Vietnam: Implications on family planning and maternity services. Eur J Contracept Reprod Health Care. 2005;10(2):111-8.

6. Organización Mundial de la Salud. Recomendaciones sobre Prácticas Seleccionadas para el Uso de Anticonceptivos. Ginebra: OMS; 2005.

7. Pierre LAS, Clapis MJ. Family Planning in a Family Health Unit. Rev. Latino-Am. Enfermagem. 2010 novdez;18(6):1161-8.

8. Hamani Y, Sciaki-tamir R, Deri-hasid T, Haimovkochman R. Misconceptions about oral contraception pills among adolescents and physicians. Hum Reprod. 2007;22(12):3078-83. 
9. Moura ERF, Silva RM. Professional competence and contraceptive care. Rev Saúde Pública. 2005; 39(5):795-801.

10. Paniz VMV, Fassa AG, Silva MC. Knowledge about contraceptives in a population 15 years or older in a Southern Brazilian city. Cad Saúde Pública. 2005;21(6):1747-60.

11. Secretaria Municipal da Saúde (CE). Relatório de Gestão 2007. Fortaleza (CE): SMS; 2007.

12. Williamson LM, Parkes A, Wight $D$, Petticrew M, Hart GJ. Limits to modern contraceptive use among young women in developing countries: a systematic review of qualitative research. Reprod Health. 2009;6(3):1-12.

13. Kraft JM, Harvey SM, Thorburn S, Henderson JT, Posner SF, Galavotti C. Intervening with couples assessing contraceptive outcomes in a randomized pregnancy and HIV/STD risk reduction intervention trial. Women's Health. 2007;17(1):52-60.

14. Mark $H$. The structure of contraceptive education and instruction within nurse led family planning clinics: a grounded theory study. J Clin Nurs. 2009; 18(18):2656-67.

15. Sousa MCR, Gomes KRO. Objective and perceived knowledge of oral contraceptive methods among adolescent mothers. Cad Saúde Pública. $2009 ; 25(3): 645-54$.

16. Santos JC, Freitas PM. Family planning under the view of development. Ciênc Saúde Coletiva. 2011;16(3):1813-20. 